\title{
Correction to: Predictive values of left ventricular mechanical dyssynchrony for CRT response in heart failure patients with different pathophysiology
}

\author{
Zhuo He, BS, ${ }^{a}$ Dianfu Li, MD, ${ }^{\text {b }}$ Chang Cui, MD, ${ }^{\text {b Hui-yuan Qin, MD, }}$ \\ Zhongqiang Zhao, BS, ${ }^{\mathrm{b}}$ Xiaofeng Hou, MD, ${ }^{\mathrm{b}}$ Jiangang Zou, MD, ${ }^{\mathrm{b}}$ \\ Ming-long Chen, MD, ${ }^{\mathrm{b}}$ Cheng Wang, MD, ${ }^{\mathrm{b}}$ and Weihua Zhou, PhD ${ }^{\mathrm{a}, \mathrm{c}}$ \\ a Department of Applied Computing, Michigan Technological University, Houghton, MI \\ b Department of Cardiology, The First Affiliated Hospital of Nanjing Medical University, Nanjing, \\ China \\ c Center for Biocomputing and Digital Health, Institute of Computing and Cybersystems, and \\ Health Research Institute, Michigan Technological University, Houghton, MI
}

doi: $10.1007 / \mathrm{s} 12350-021-02834-0$

CORRECTION TO: JOURNAL OF NUCLEAR CARDIOLOGY

HTTPS://DOI.ORG/10.1007/S1 2350-021-02796-3

Corresponding authors for this should be listed as Weihua Zhou, PhD and Cheng Wang, MD.
Publisher's Note Springer Nature remains neutral with regard to jurisdictional claims in published maps and institutional affiliations.

The original article can be found online at https://doi.org/10.1007/ s12350-021-02796-3.

Reprint requests: Cheng Wang, MD, Department of Cardiology, The First Affiliated Hospital of Nanjing Medical University, Guangzhou Road, Nanjing 210029, China; wangcheng361@126.com and Weihua Zhou, PhD, Center of Biocomputing and Digital Health, Institute of Computing and Cybersystems, and Health Research Institute, Michigan Technological University, 1400 Townsend Dr, Houghton, MI, 49931;whzhou@mtu.edu.

J Nucl Cardiol 2022;29:895.

$1071-3581 / \$ 34.00$

Copyright (C) 2021 American Society of Nuclear Cardiology. 